\title{
SMALLPOX INOCULATION IN COLONIAL NEW JERSEY: A CONTEMPORARY ACCOUNT
}

\author{
BY LARRY R. GERLACH \\ Mr. Gerlach is a candidate for the Ph.D. in History \\ at Rutgers University.
}

I

$\mathrm{N}$ Colonial America, theological presuppositions, occult notions, and superstitions plagued medical science; physicians treated fits, fevers, and fluxes instead of specific diseases; bleeding, sweating, and vomiting were standard treatments for illness ranging from the ague to consumption; quacks, midwives, and preachers practiced "physick" alongside skilled doctors." It is little wonder that early settlers had more to fear from the perils of pathogenic organisms than from hostile Indians and natural calamities. The most dreaded scourge of all was smallpox-a disease that ravaged the population of North America (both indigenous and immigrant) throughout the seventeenth and eighteenth centuries. ${ }^{2}$

But if variola was indeed a microscopic agent of death and decimation, it was also a stimulus to the advancement of medical science. It was, after all, a smallpox epidemic that prompted the publication of the first medical essay printed in North America ${ }^{3}$ and provided the occasion for the initial major test of variolization in the annals of Western medical history. Inoculation for the prevention of smallpox originated in Boston in $172 \mathrm{I}$, when, at the prompting of Cotton Mather, Zabdiel Boylston inoculated his only son and two Negro servants, thereby launching a campaign in which 240 individuals eventually were treated. ${ }^{4}$ Recurring epidemics were grim

\footnotetext{
${ }^{1}$ For an excellent discussion of medical practice in early America, see Richard $\mathrm{H}$. Shryock, Medicine and Society in America: 166o-r860 (New York, 1960).

${ }^{2} \mathrm{~A}$ general account is John Duffy, Epidemics in Colonial America (Baton Rouge, 1953 ).

${ }_{3}$ Thomas Thacher, $A$ Brief Rule to Guide the Common People of New-England How to order themselves and theirs in the Small Pocks, or Measels (Boston, November 21 , $1677 / 8)$.

${ }^{4}$ See John B. Blake, "The Inoculation Controversy in Boston, I $721-1722$," New
} 
inducements to more extensive inoculation. In eighteenth century New Jersey alone, untold lives were claimed by at least four major epidemics, including a seven-year outbreak which began at Burlington in $1715 .^{\circ}$

Medical statistics for the colonial period are notorious for their unreliability. ${ }^{6}$ Yet by any measurement, smallpox looms as a deadly disease. The precious few extant sources indicate a smallpox mortality rate ranging anywhere from fifteen to fifty percent. Those fortunate enough to survive its devastation more often than not bore readily noticeable scars for the remainder of their lives. On the other hand, only one to two percent of those inoculated died from the disease. Inoculation, however, was not completely safe. The rather undeveloped state of medical knowledge and unsophisticated inoculating techniques involved the very real danger of being stricken with several days of fever or at worst of contracting a mild case of smallpox. ${ }^{7}$ Such risks appear to be small when compared to the alternatives of deformation or death. But society as a whole was skeptical of homeopathic medicine, and debates on the merits of the practice reverberated throughout the colonies in the second third of the eighteenth century. In New Jersey the Reverend Colin Campbell created a commotion in I 759 by inoculating his own family in order to demonstrate to the community the benefits of variolization. A year later "Americus" wrote in the Pennsylvania Journal that thousands in New Jersey had been spared the dread disease by the "new method of treating those under Inoculation." It was reported that only one in seven hundred died and only one in one hundred received the full impact of the disease, "while in the common way

England Quarterly (1952); Otho T. Beall, Jr., "Cotton Mather, the First Significant Figure in American Medicine," Bulletin of the History of Medicine (1952); and R. H. Fitz, "Zabdiel Boylston, Inoculator," Johns Hopkins Hospital Bulletin (1911).

${ }^{5}$ David L. Cowen, Medicine and Health in New Jersey: A History (Princeton, 1964), p. 2.

${ }^{6}$ An excellent bibliographical guide to works dealing with medicine in Colonial America, which includes brief sketches of leading figures, is Whitfield J. Bell, Jr., Early American Science: Needs and Opportunities (Williamsburg, 1955). Also valuable is the pioneering work of Brooke Hindle, The Pursuit of Science in Revolutionary America, ${ }^{1735-1789}$ (Chapel Hill, I956).

${ }_{7}$ A noteworthy exception was Jonathan Edwards, who, while President of the College of New Jersey (Princeton), succumbed in $175^{8}$ following inoculation. 
of Infection, I dies out of 5. " The overwhelming evidence of the success of inoculation, coupled with the development of a nascent medical profession after mid-century, ${ }^{9}$ did much to convince the general populace of the merits of variolization.

There were several inoculation techniques which attained wide usage in the colonies. The earliest method-basically an imitation of European practice-was to insert purulent matter gathered from a pustule on a pox victim into a small scratch in the skin of the patient. The wound was then bound. This procedure proved to be unsatisfactory: the infusion often failed to take because the matter either dried out or became contaminated during the interval between gathering and implantation. These shortcomings were largely overcome by a second, more successful method. In this process a piece of thread moistened in a pustule was dried by exposure to air and stored in a sanitary container for future use. When needed, the thread was imbedded in an incision and secured with a bandage. ${ }^{10}$ Dr. Stephen Wickes, eminent New Jersey physician-historian, relates that the individual inoculated was then warmly clothed, put to bed, and given medication designed to hasten pustulation and promote profuse perspiration. ${ }^{11}$ It was also common practice to designate isolated buildings as temporary pesthouses in which those inoculated were quarantined until they fully recovered.

The paucity of skilled physicians made the treatment of even the most elementary illness-let alone smallpox-hazardous. So great was the demand for trained doctors that professional distinctions paled into virtual non-existence. Medicine was often a part-time job: the butcher, the preacher, the baker, the teacher, all practiced the healing art. Of the approximately 3,500 practitioners of medicine in the colonies on the eve of the War for American Independence, not

${ }^{8}$ Cowen, Medicine and Health, p. 3.

${ }^{9}$ Dr. John Morgan in 1765 founded the first medical school in the colonies at the College of Philadelphia (University of Pennsylvania). A year later, fourteen "Practitioners of Physic and Surgery" from East Jersey, distressed by the "low state of Medicine" in the colony, founded the Medical Society of New Jersey-the first organization of its kind in America.

${ }^{10}$ Fred B. Rogers and A. Reasoner Sayre, The Healing Art: A History of the Medical Society of New Jersey (Trenton, 1966), pp. 2-3.

${ }^{11}$ Stephen Wickes, History of Medicine in New Jersey and of its Medical Men, From the Settlement of the Province to A.D. ${ }_{1} 800$ (Newark, 1879), pp. 3 I-32. 
more than 400 had received any formal training whatsoever. And of these only about half held medical degrees. ${ }^{12}$ The situation was similar in New Jersey: before I 800, only 4I out of approximately 300 doctors had received training beyond the apprentice stage. ${ }^{13}$ Given the acute shortage of skilled physicians and the rurality of colonial society, the individual, of necessity, had to rely upon his own resources and intuition to combat the ravages of disease. While it must have been difficult to distinguish quackery from trustworthy medication, the advent of a flourishing printing profession in the eighteenth century made possible the wide dissemination of medical information and therapeutic techniques. Newspaper articles, pamphlets, guides, and manuals enabled the colonist better to diagnose and treat illness. Many publications were devoted to smallpox.

In this regard a description of eighteenth century inoculation procedures located among the Hendrickson Family Papers in the Special Collections Department of the Rutgers University Library assumes considerable significance. ${ }^{14}$ This manuscript is ostensibly a rendition of a pamphlet entitled "The General Method of Enoculation as now Practised." However, investigation has failed to produce any evidence to indicate that such a pamphlet was ever printed. ${ }^{15} \mathrm{We}$ may, then, assume that the document was printed locally (probably in Woodbridge) and was intended for a limited distribution. It is also highly unlikely that the inoculation techniques delineated in the manuscript prescribe any treatment other than that which had become common practice. Nonetheless, it is the only known account of variolization in Colonial New Jersey and is especially interesting because of its vivid and detailed exposition of the inoculation procedure from initial preparation to the treatment of after-effects.

\footnotetext{
${ }^{12}$ Shryock, Medicine and Society, p. 9; also Whitfield J. Bell, Jr., "Medical Practice in Colonial America," Bulletin of Medical History (1957).

${ }^{13}$ Cowen, Medicine and Health, p. 8.

14 This undated and unsigned manuscript was most likely written by or in the possession of Daniel Hendrickson ( $1753-1787$ ), a prominent Middletown merchant. In any event the internal evidence clearly indicates that the document is the product of the third quarter of the eighteenth century.

${ }^{15}$ Robert B. Austin, comp., Early American Medical Imprints: A Guide to Works

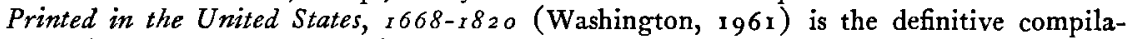
tion of colonial medical publications.
} 
[The General Method of Enoculation as now Practised]

We have a pamphlet printed here Called the general Method of Enoculation as now practised. [It] is as follows. The first thing noticed is a quantity and quality of food which the patients make use of; and in this the operators generally agree, ordering them all to abstain wholely from flesh, fish, cheese, Butter, Eggs, Pepper \& all Spices; from Every kind of Spiritous liquors whether mixt or Raw which destroy more than the plague; from wine, Syder and all mault Liquors: and to Live upon Water grewel, thin milk porridge, skimmed milk, weak green Tea, or Coffe[e], with dry toast, dry Bread, or ordinary Cake; Honey \& bread or dry bread and water only, for Breakfast; which last is prefered to any other fare by all who can or will Submit to it. For dinner they are allowed plain or plumb Pudden or light dumplings, with a Sause of boil'd flour \& water, and a little vinegar, Sweetened with Sugar or honey; Rice Pudden, apple pudden, or pye, Rice milk, roasted potatoes, or turnups with salt; and any kind of fruits Greens or Roots out of the kitchin gardens, Except on the Phisical days. For drink they use water with a toast in it, milk and water, Lemon and water, or Imperial water. For Supper, the Same as in the morning, but it is best to go to bed without any [thing to eat]. This Regimen has been Strictly adhered to by most of the patients from the time they Began the preparation, till the disorder was quite over but now Some of them are permitted to take flesh, and malt liquors when the pox is out; [but] only at first, [and] in a Sparing manner. Many of the opperators prepare a week before they Enoculate; others Inoculate first, and Immediately begin the preparation as above. Which of these methods is best Experience must determine but in Each of them the following medicine is generally administered [:] Ten grains of Calomel and two grains of Factitious Cinnabar, or Apothecarys mineral, ${ }^{16}$ well mixt together with the point of a knife, and put in a little Jelly or the pulp of a Roasted apple as which is the best way made up into two or three pills, with a few crumbs of Bread moisten'd. [The pills] are given to persons of a Strong Constitution, or gross habit of Body from Sixteen to fifty years of Age. It is hardly

16 This compound constitutes a cathartic (a purgative or cleansing agent) and an anthelmintic (a medication to expel or destroy intestinal worms). 
Judged Safe to give these powders to Infants (tho some of the opperators do it). For these [infants] therefore a Dram of manna ${ }^{17}$ is dissolved in warm milk or water, is ordered for Eight or ten days together unless when the nurse who gives Suck is prepared, which is deem'd sufficient. But Some children from one to five or Six years old take from one grane to two and a half of the powders [;] from six to ten, four grains [;] from Ten to Sixteen, six grains as their Constitutions will Bear which rule is always Carefully to be observed, with Respect to grown persons also. Those above Six take six or Eight grains according to their Strength and manner of living. Such as take these powders, should not Suffer them to touch their teeth or gums which is Easily prevented when they are made into pills. The first dose of powders is taken at night when the patient is going to bed which [is] Suppose to be wednesday night or Thursday morning. He takes one ounce of glaubers Salts ${ }^{18}$ dissolv'd in a Tea cup of warm water: drinking freely afterwards of thin water gruel, Cheese, Whey or weak green Tea till he has at least six or Eight Stools in So many hours. On Fryday night he takes another dose of powders, on Saturday morning the Salts, on Sunday night the third dose, with Salts on Monday morning as before. If the powder should be vomitted up again Immediately, then he takes the Salts as Soon as the Sickness is over or if one ounce of Salts does not purge Brisk Enough to carry of [f] the powders, then more [is] taken to the quantyty of two or three ounces if needfull. This is done to prevent a Salivation, ${ }^{19}$ which very rarely happens if the Salts work freely, and the patient avoids Catching cold. But if it Should, which may be Easily known by Soreness of the Gums, looseness of the teeth \& an Inclanation to Spitting, half an ounce of Flour of Brimstone in a little warm milk repeatedly Taken is an Effectual remedy.

When the Salts work or purge violently, then the Patient [is] to rest a day or two more between the Doses. Some of the operators give a less[er] quantity of the powders than [do] others. One, Seldom [gives] above six grains in Either the first or Second \& ten or twelve in the last. Others make no difference but give an Equal

17 The exudate of the flowering ash used as a mild laxative.

${ }^{18}$ Glauber's Salt served as a cathartic, aperient (a laxative), and a diuretic (a medicine which increases the secretion and discharge of urine).

${ }^{19}$ The reference here is to ptyalism, the excessive secretion of saliva. 
Quantyty in all their Doses whether they prepare before Inoculation or after it. The patient being free from a fever, which is Carefully observ'd, the opperation is thus perform'd. A person with the Eruption upon him when the disorder is near the heigth, is Brought into the Room where the Patient is. The Operator having opened a Pustule on the person Infested takes out Some matter on the point of the Lancet and then Raises up the Cuticle or outer skin on the arm of the patient between the Elbow and Shoulder in two places So as Just to make the blood appear: leaving Some of the matter in Each of the Incissions, without applying Either plaster or bandage. Others carry the matter in a Small glass viol and perform the operation as above. The matter Should always be taken from the most healthy person that can be met with \& from the mildest sort of pock. The Effect it has is known Sometimes in a few hours by Sharp pains darting up to the Shoulder \& a Shivering through the body, a red tumour on the arm or a Small rysing where the matter was apply'd. In others these Symtoms are two or three days before they come on but in this time the operators generally pretend to foretel with Some certainty what will be the Event of the Operation. If the discolouration round the places of Incission be very large then they say the Eruption will be but Small. If on the contrary it is Small; then they order pills and Salts to be plentyfully administered, because they Expect a Large Eruption in Eight or nine days. The parts Infected frequently Rise up with a Large tumor and Severel little Red pustules appear round them; the Arms Continue sore and Stiff with pains in the head and back: a Shivering and Sometimes a fever [occur]. Then other pustules are thrown out in different parts of the body which in A few Days are filled with a thick white matter. This shews the Disorder to be at its heigtht. At this Period some of the operators offer a fourth Dose of Powders; but the most Successfull give only the three first doses though they all agree in giving one dose of Salts now \& two or three more afterwards at a weeks Distance from Each other and in advising their patients to be moderate in diet. But as many persons pay no regard to Such advise they are frequently troubled with Coulds, Fevers \& other disorders which are likely to terminate in Consumptions and Death. If the patient has none of the above Symtoms by the Sixth or Seventh day 
after the opperation, it is then perform'd again. Sometimes [it is performed] on the [same] arm or on the other Just as the operator think proper but always in fresh places. After three or four Such operations if no tumour or other Symtoms appears, the operator then concludes that the person has had the Disorder, or looks upon him to be past the Infection by his art, and Sends him amoung Such as have the disorder in the most malignant manner that he may if Possible to Catch it the natural way. At the Same time he assures him that if he has it now it will be very Slightly as his body is prepar'd; or if it Should Even fall heavy on him at first yet the Repellent is generally found sufficient to prevent its dreadfull Consequences. This pill is made as follows. Take ten grains of Camphor pounded in a morter with a few drops of Spirits of wine to which add twenty grains of the best Succortine Aloes, and ten grains of Kerme's mineral. ${ }^{20}$ After these Ingredients are well pounded together, the mass is made into four pills of Ten grains Each. One of these is given about the fourth or fifth night after Inoculation and the next morning Salts Sufficient to Carry it of [f]. If the patient is of a Gross habit or Strong constitution or has lived high, he takes two more the Sixth night, and Sometimes the fourth, a night or two after with Salts, as Before. ... These pills the operators say carry of $[\mathrm{f}]$ the offended matter which Causes so Great an Eruption in gross bodys: so that the number of pustules is lessened, and the Confluence of them thereby prevented. To such as have them in the Natural way, they are administered with remarkable Success and are doubtless a very remarkable composition. While the pock is Breeding the Fever is violent or likely to be so. A Mixture by some cold punch is given to the patients. This is made by boiling a pint of oats in four pints of water till they are ready to burst. Having Strain'd of $[f]$ the Liquor then ad[d] an ounce of Salt peter and make it pallitable with Sugar or honey and a little lemmon Juce or Cream of Tarter. . . . Half a pint is taken at a draught Just when the patient is going to bed and afterwards as much as he pleases. This mixture is to abate a fever.

${ }^{20}$ This preparation was utilized as a purgative and tonic. 